\title{
Microbial Characterization of Yeast Isolates Recovered from Blood of Patient Admitted in ICU in a Tertiary Care Hospital
}

\author{
Saurabh Jain*, Sanyogita Jain, Atul Rukadikar, Saurabh G. Agarwal \\ and Mamata Sarwaria
}

\author{
Department of Microbiology, Chirayu Medical College and Hospital, Bhopal, MP, India \\ *Corresponding author:
}

\begin{tabular}{|c|c|}
\hline & A B S T R A C T \\
\hline $\begin{array}{l}\text { Key w o r d s } \\
\text { Microbial } \\
\text { characterization } \\
\text { of yeast, Fungal } \\
\text { bloodstream } \\
\text { infections (BSIs). }\end{array}$ & $\begin{array}{l}\text { Fungal bloodstream infections (BSIs) are severe diseases that lengthen hospital stay, } \\
\text { have elevated morbidity and mortality and increase medical care costs. Their } \\
\text { incidence has recently increased, likely due to an increase in the number of susceptible } \\
\text { hosts. The main aim of this study to characterization of candida isolated from blood from } \\
\text { patient admitted in ICU. Our Objectives was to speciate candida isolated from the clinical } \\
\text { sample \& to do susceptibility testing of candida isolates using VITEK } 2 \text {. The present study } \\
\text { Prospective non-randomized, observational study was conduct in Department of }\end{array}$ \\
\hline Article Info & $\begin{array}{l}\text { Microbiology, medical college \& hospital in Central India for a period of } 1 \text { year (April 01, } \\
2016 \text { - March 31, 2017). Non-albicans candida were the most common cause of blood }\end{array}$ \\
\hline $\begin{array}{l}\text { Accepted: } \\
\text { 23 May } 2017 \\
\text { Available Online: } \\
\text { 10 June } 2017\end{array}$ & $\begin{array}{l}\text { stream infection by yeast. Risk factor for yeast infection found in our study were Head } \\
\text { injury, Burn, Low birth weight, Birth asphyxia, Malignancy, Congenital heart defect. Out } \\
\text { of } 27 \text { yeast isolates Candida tropicalis were } 8(29.62 \%) \text {, Candida krusie } 7(25.92 \%) \text {, } \\
\text { Candida albicans } 5 \text { ( } 18.52 \%) \text {, Candida glabrata } 3(11.11 \%) \text {, Candida parapsilosis } 2 \\
(7.41 \%) \text {, Trichosporon asahii } 1 \text { (3.7\%), Candida kefyr } 1(3.7 \%) \text {. }\end{array}$ \\
\hline
\end{tabular}

\section{Introduction}

The incidence and prevalence of invasive fungal infections have increased since the 1980 s, especially in the large population of immunocompromised patients and/or those hospitalized with serious underlying diseases (Michael et al., 2011). Candida species belong to the normal microbial flora of an individual's mucosal oral cavity, gastrointestinal tract and vagina, and are responsible for various clinical manifestations from mucocutaneous overgrowth to bloodstream infections (Enoch et al., 2006; Pfaller et al., 2004). Fungal bloodstream infections (BSIs) are severe diseases that lengthen hospital stay, have elevated morbidity and mortality and increase medical care costs. Their incidence has recently increased, likely due to an increase in the number of susceptible hosts (Laupland et al., 2005; Carey et al., 2008).

Candida spp. represent the principal aetiology of fungal BSIs and even though Candida albicans was reported as the most common species causing Candidaemia, an epidemiological shift towards non-albicans candida species has been reported in various geographical areas (Cugno et al., 2012; Sardi et al., 2013). 
More than 17 different Candida species are known to be aetiological agents of human infection; however, more than $90 \%$ of invasive infections are caused by Candida albicans, Candida glabrata, Candida parapsilosis, Candida tropicalis and Candida krusei. The expanding population of immunocompromised patients that use intravenous catheters, total parenteral nutrition, invasive procedures and the increasing use of broad-spectrum antibiotics, cytotoxic chemotherapies and transplantation are factors that contribute to the increase of these infections (Abi-Said et al., 1997). Invasive Candida infections are also often seen after immunosuppressive treatments and transplantation procedures. The overall increase in nosocomial candidiasis observed worldwide in recent decades has been accompanied by a change in the epidemiology of these infections, characterized by a progressive shift from a predominance of Candida albicans to nonC. albicans Candida species that exhibit resistance to commonly used antifungal agents such as fluconazole (Asmundsdottir et al., 2002; Mokaddas et al., 2007; Poikonen et al., 2007; Oberoi et al., 1997).

Currently, an increase in the number of yeasts that are resistant to antifungal drugs is recognized worldwide; therefore, the use of in vitro laboratory tests may aid the doctor in choosing an appropriate therapy (Arunaloke et al., 2008). The main aim and objectives of this study includes, characterization of Candida isolated from blood from patient admitted in ICU. And to speciate Candida isolated from the clinical sample. Also to do susceptibility testing of Candida isolates using VITEK 2

\section{Materials and Methods}

Settings: Department of Microbiology, medical college and hospital in Central India.

\section{Study period}

1 year (April 01, 2016 - March 31, 2017).

\section{Study design}

Prospective, non-randomized, observational study on patients visiting the hospital.

\section{Inclusion criteria}

Isolates of Candida recovered from blood samples from ICU.

Patients of all age groups.

\section{Exclusion criteria}

Isolation of Candida from samples other than blood.

Isolation of Candida other than ICU.

\section{Procedure}

\section{Specimen}

5-10 ml of Blood collected in Blood culture bottle.

\section{Processing}

Blood culture bottle were be place in the Incubator at $37^{\circ} \mathrm{C}$ within $30 \mathrm{~min}$ of collection.

All bottles were be subcultured on solid media after 1,2,3,7 days of incubation/ examine macroscopically for evidence of growth after similar incubation, make a smear and subculture on solid media [Blood agar and Sabouraud's Dextrose agar (SDA)] (Arunaloke et al., 2008).

Identification of Candida spp. will be done using standard manual methods as described by Jagdish chander (2011) and the identification will be done as follows: 


\section{Colony characteristics}

Smooth, white or cream colored colonies will be identified as those of Candida.

\section{Gram's staining}

Round to oval Gram positive budding cells with or without pseudohyphae will be considered as positive for Candida.

Germ tube test (Arunaloke et al., 2008; Chander et al., 2011)

The observation of germ tube production (Reynolds-Braude phenomenon) has been used as a method of presumptive identification of Candida albicans isolates from clinical samples. $C$. albicans (ATCC90028) used as a Positive control and C. parapsilosis (ATCC22019) as Negative control.

Chlamydospore formation (Arunaloke et al., 2008; Chander et al., 2011)

Morphological characters on cornmeal agar including the pattern of growth and presence or absence of chlamydospores will be observed for identification of Candida species. Terminal chlamydoconidia seen in $C$. albicans and $C$. dubliniensis, in C. tropicalis abundant pseudohyphae, pine forest arrangement, blastoconidia formed at or in between septa, in $C$. parapsilosis giant hyphae,blastospores at nodes, in C. krusei elongated yeasts, abundant pseudohyphae (matchstick-like appearance), in C. glabrata and C. famata yeasts only, in C. guilliermondi scant pseudohyphae with chains of blastoconidia in C. lusitanie-short, distinctly curved pseudohyphae with occasional blastoconidia at septa. C. albicans (ATCC90028) used as a Positive control and C. parapsilosis (ATCC22019) as Negative control.
Sugar fermentation test (Arunaloke et al., 2008)

Candida species ferment carbohydrates anaerobically. Liquid fermentation medium containing peptone $(1 \%)$, sodium chloride $(0.5 \%)$, Andrade's indicator $(0.005 \%)$ was used. It will be sterilized by autoclaving at $120^{\circ} \mathrm{C}$ for $15 \mathrm{~min}$. at 15 pounds pressure. Filter sterilized carbohydrates (glucose, lactose, sucrose, maltose, galactose and trehalose from HiMedia, Mumbai) at concentration of $2 \%$ will be added to the medium. Sterile Durham's tube, to capture gas, will be placed in test tube with $5 \mathrm{ml}$ of the medium. Inoculum will be prepared by suspending yeast grown on sugar free medium.

Each carbohydrate broth will be inoculated with approximately $0.1 \mathrm{ml}$ of heavy inoculum of the Candida. The tubes will be incubated at $25^{0} \mathrm{C}$ upto 1 week. Tubes will be examined every $48-72 \mathrm{hrs}$ interval to see the production of acid (pink color) and gas (in Durham's tube). Fermentation will be determined by observing change in colour and / or production of gas in Durham's tube. Interpretation of results will be done as described by Arunaloke Chakrabarti et al., (2008).

Sugar assimilation test (Arunaloke et al., 2008)

It is an aerobic process in which carbon and nitrogen compounds are utilized with oxygen as final electron acceptor. Carbohydrates used for assimilation test will be glucose, lactose, galactose, maltose, sucrose and trehalose, (HiMedia, Mumbai). The Disc impregnation Pour plate Auxanographic method of Wickerham and colleagues which has withstood the test of time and easier to perform will be followed. 
Preparation of YNB and agar separately will be done as described. 24-48 hrs growth of Candida will be used to prepare a suspension and $2 \mathrm{ml}$ of this will be added to $18 \mathrm{ml}$ of molten agar (cooled to $45^{\circ} \mathrm{C}$ ) and mixed well. The entire volume will be poured into a $90 \mathrm{~mm}$ petri plate. The various carbohydrate impregnated discs will be placed onto the surface of the agar plate. The plates will be incubated at $37^{\circ} \mathrm{C}$ for $3-4$ days. The presence of growth around the disc will be considered as positive for that particular carbohydrate. Growth around glucose disc will be recorded first which will serve as positive control (viability of yeast). Interpretation of carbohydrate assimilation and species identification will be done as detailed by Arunaloke Chakrabarti et al., (2008).

\section{CHROM agar Candida medium}

It is a selective and differential chromogenic medium used for identification of various Candida species. The following procedure will be followed: Suspected Candida colonies will be inoculated onto CHROM agar (HiMedia). Plates will be incubated at $30^{\circ} \mathrm{C}$ for 48 to 72 hours. Plates will be examined for the colour of colonies for presumptive identification. The following colour of colonies may be seen: $C$. albicans Light green, $C$. dubliniensis Dark green, $C$. glabrata pink to purple, $C$. krusei Pink, $C$. parapsilosis cream to pale pink, $C$. tropicalis blue with pink halo

Antifungal susceptibility testing by VITEK 2 (Pfaller et al., 2007)

Antifungal susceptibility testing will be determine by Vitek 2 for all isolates against Amphotericin B (AMB), Fluconazole (FLC) Voriconazole (VRC), Capsofungin, Micofungin, Flucytocine, as described by the manufacturer.

\section{Results and Discussion}

Non-albicans candida were the most common cause of Blood stream infection by yeast. Yeast infection were slightly higher prevalence in male $(55.56 \%)$ as compare to female (44.44\%). 15 yeast strains were isolated from Medicine ICU, 6 from Pediatrics ICU, 6 from Surgical ICU as shown in Table 1.

Percentage positivity for yeast isolates in clinical samples was $2.25 \%$ (27 yeast isolates /1200 blood samples). Out of 27 yeast isolates Candida tropicalis were 8 (29.62\%), Candida krusie 7 (25.92\%), Candida albicans 5 (18.52\%), Candida glabrata 3 (11.11\%), Candida parapsilosis 2 (7.41\%), Trichosporon asahii 1 (3.7\%), Candida kefyr $1(3.7 \%)$. Antifungal susceptibility for each isolates shown in table 2.

Table.1 Distribution of candida according to gender \& ward

\begin{tabular}{|c|c|c|c|}
\hline & Male & Female & Total \\
\hline MICU & 10 & 5 & 15 \\
\hline SICU & 2 & 4 & 6 \\
\hline PICU & 3 & 3 & 6 \\
\hline Total & $15(55.56 \%)$ & $12(44.44 \%)$ & 27 \\
\hline
\end{tabular}


Table.2 Percentage positivity of yeast isolates and their antifungal susceptibility testing

\begin{tabular}{|c|c|c|c|c|c|c|c|c|}
\hline Species of Candida & \multirow{2}{*}{$\begin{array}{l}\text { Total } \\
\text { no. (27) }\end{array}$} & \multirow{2}{*}{ Percentage } & \multicolumn{5}{|c|}{ Antifungal susceptibility test (in percentage) } \\
\cline { 4 - 9 } & & $\begin{array}{c}\text { FLUCO- } \\
\text { NAZOLE }\end{array}$ & $\begin{array}{c}\text { VORICO- } \\
\text { NAZOLE }\end{array}$ & $\begin{array}{c}\text { CAPSO- } \\
\text { FUNGIN }\end{array}$ & $\begin{array}{c}\text { MICA- } \\
\text { FUNGIN }\end{array}$ & $\begin{array}{c}\text { Ampho- } \\
\text { tericin B }\end{array}$ & $\begin{array}{c}\text { FLUCYTO- } \\
\text { SINE }\end{array}$ \\
\hline Candida tropicalis & 08 & 29.62 & 71.43 & 85.71 & 71.43 & 71.43 & 85.71 & 71.43 \\
\hline Candida krusie & 07 & 25.92 & 14.28 & 85.71 & 28.57 & 57.14 & 57.14 & 57.14 \\
\hline Candida albicans & 05 & 18.52 & 80 & 80 & 60 & 60 & 60 & 60 \\
\hline Candida glabrata & 03 & 11.11 & 33.33 & 100 & 33.33 & 66.67 & 100 & 100 \\
\hline Candida parapsilosis & 02 & 7.41 & 50 & 50 & 50 & 50 & 50 & 100 \\
\hline Trichosporon asahii & 01 & 3.7 & 0 & 100 & 0 & 100 & 100 & 100 \\
\hline Candida kefyr & 01 & 3.7 & 100 & 100 & 100 & 100 & 100 & 0 \\
\hline
\end{tabular}

Candida species are the fourth leading cause of Hospital acquired bloodstream infection (BSI) in the United States, accounting for $8 \%$ to $10 \%$ of all BSIs acquired in the hospital (Wisplinghoff et al., 2004). These yeasts are commensal in healthy humans and may cause systemic infection in immunocompromised situations due to their great adaptability to different host niches. Bassetti et al., (2006) also find increase prevalence of non albicans Candida in their study. C. tropicalis was the most predominant yeast infection found in our study as observed by Rajendra Kothavade et al., (2010).

Candida krusie was found to most resistant $(85.62 \%)$ to Fluconazole in our study. $C$. tropicalis show $71.43 \%$ C. albicans $80 \%, C$. parapsilosis $50 \%$, C. glabrata $33.33 \%$ susceptibility to fluconazole. We also isolate a Trichosporon asahii strain that is resistant to Fluconazole.

Candida tropicalis was most susceptible to Amphotericin B and Voriconazole. Candida krusie was most susceptible to Voriconazole. Candida albicans was most susceptible to Fluconazole and Voriconazole. Candida glabrata was most susceptible to Amphotericin B, Voriconazole and Flucytosine.

In conclusion, Candida tropicalis \& krusie were the leading cause of blood stream infection in the presence of risk factor in our study. Resistance to Fluconazole was high for treatment of candida infection. Amphotericin B \& Voriconazole can be used as a good option for the treatment of candida infection.

\section{References}

Abi-Said, D., Anaissie, E., Uzun, O., Raad, I., Pinzcowski, H., Vartivarian, S. 1997. The epidemiology of hematogenous candidiasis caused by different Candida species. Clin Infect. Dis., 24: 1122-1128.

Arunaloke Chakrabarti, et al. 2008. Medical Mycology Laboratory Procedures. PGIMER, Chandigarh, 57- 68.

Asmundsdottir, L.R., Erlendsdottir, H., Gottfredsson, M. 2002. Increasing incidence of candidemia: results from a 20-year nationwide study in Iceland. $J$. Clin. Microbiol., 40: 3489-3492.

Asmundsdottir, L.R., Erlendsdottir, H., Gottfredsson, M. Nation- wide study of candidemia, antifungal use, and antifungal drug resistance in Iceland, 2000 to 2011. J. Clin. Microbiol., 51: 841-848.

Bassetti, M., Righi, E., Costa, A., Fasce, R., Molinari, M.P., Rosso, R., et al. 2006. Epidemiological trends in nosocomial candidemia in intensive care. BMC Infect. Dis., 6: 21.

Carey, A.J., Saiman, L., Polin, R.A. 2008. Hospital-acquired infections in the NICU: 
epidemiology for the new millennium. Clin. Perinatol., 35: 223 - 49.

Chander, J. 2011. Candidiasis. Textbook of Med. Mycol., 3rd edition 275: 507-530.

Cugno, C., Cesaro, S. 2012. Epidemiology, risk factors and therapy of candidemia in pediatric hematological patients. Pediatr. Rep., 4: e9

Enoch, D.A., H.A. Ludlam and N.M. Brown. 2006. "Invasive fungal infections: a review of epidemiology and management options" J. Med. Microbiol., 55: 809-818.

Laupland, K.B., Gregson, D.B., Church, D.L. et al. 2005. Invasive Candida species infections: a 5 year population-based assessment. J. Antimicrob. Chemother., 56: $532-7$

Michael, A., Pfallera, David Andesb, Maiken, C., Arendrupc, Daniel, J., Diekemaa, et al. 2011. "Clinical breakpoints for voriconazole and Candida spp. revisited: review of microbiologic, molecular, pharmacodynamic, and clinical data as they pertain to the development of species-specific interpretive criteria" Diag. Microbiol. Infect. Dis., Volume 70, Issue 3, Pages 330-343.

Mokaddas, E.M., Al-Sweih, N.A., Khan, Z.U. 2007. Species distribution and antifungal susceptibility of Candida bloodstream isolates in Kuwait: a 10-year study. $J$. Med. Microbiol., 56: 255-259.

Oberoi, J.K., Wattal, C., Goel, N., Raveendram, R., Datta, S., Prasad, K. 2012. Non-albicans Candida species in blood stream infections in a tertiary care hospital at New Delhi, India. Indian J. Med. Res., 136: 997-1003.

Ortega, et al. 2011. "Physical fi tness levels among European adolescents: the
HELENA study" Br. J. Sports Med., 45: 20-29. doi:10.1136/bjsm.2009.062679

Pfaller, M.A., D.J. Diekema, G.W. Procop, and M.G. Rinaldi. 2007. Multicenter comparison of the VITEK 2 antifungal susceptibility test with the CLSI broth microdilution reference method for testing amphotericin B, flucytosine, and voriconazole against Candida spp. $J$. Clin. Microbiol., 45: 3522-3528.

Pfaller, M.A., Diekema, D.J. 2004. Twelve years of fluconazole in clinical practice: global trends in species distribution and fluconazole susceptibility of bloodstream isolates of Candida. Clin. Microbiol. Infect., 10 Suppl 1:11 - 23.

Poikonen, E., Lyytikainen, O., Anttila, V.J. et al. 2007. Secular trend in candidemia and the use of fluconazole in Finland, 20042007. BMC Infect. Dis., 10: 1-7.

Rajendra, J., Kothavade, M.M. Kura, Arvind, G., Valand and M.H. Panthaki, et al. 2010. Candida tropicalis: its prevalence, pathogenicity and increasing resistance to fluconazole. J. Med. Microbiol., 59: 873880

Sardi, J.C.O., L. Scorzoni, T. Bernardi, A. M. Fusco-Almeida and M.J.S. Mendes. Giannini. "Candida species: current epidemiology, pathogenicity, biofilm formation, natural antifungal products and new therapeutic options" J. Med. Microbiol., 62: 10-24.

Wisplinghoff, H., T. Bischoff, S.M. Tallent, H. Seifert, R.P. Wenzel, and M.B. Edmond. 2004. Nosocomial bloodstream infections in US hospitals: analysis of 24,179 cases from a prospective nationwide surveillance study. Clin. Infect. Dis., 39: 309-317.

\section{How to cite this article:}

Saurabh Jain, Sanyogita Jain, Atul Rukadikar, Saurabh G. Agarwal, Mamata Sarwaria. 2017. Microbial Characterization of Yeast Isolates Recovered from Blood of Patient Admitted in ICU in a Tertiary Care Hospital. Int.J.Curr.Microbiol.App.Sci. 6(6): 1652-1657. doi: https://doi.org/10.20546/ijcmas.2017.606.193 